Atos de Pesquisa em Educação - ISSN 1809-0354

Blumenau - vol. 11, n. 2, p.444-467 ago./nov. 2016

DOI: http://dx.doi.org/10.7867/1809-0354.2016v11n2p444-467

\title{
MULHERES EGRESSAS DA EJA NA UNIVERSIDADE: ENTRE INTEMPÉRIES, SONHOS POSSÍVEIS E INÉDITOS VIÁVEIS
}

\author{
FEMALE FORMER STUDENTS FROM EJA AT UNIVERSITY: AMID \\ DIFFICULTIES, REALISTIC EXPECTATIONS AND UNTESTED FEASIBILITIES
}

\author{
DIAS, Alder de Sousa \\ alder.dias@unifap.br \\ UNIFAP - Universidade Federal do Amapá \\ OLIVEIRA, Júlia Milena da Paixão \\ julia-milena2011@bol.com.br \\ UEAP - Universidade do Estado do Amapá \\ SANTOS, Manoel Raimundo dos \\ santosmanoel2366@gmail.com \\ UEAP - Universidade do Estado do Amapá \\ SANTOS, Odite das Graças Brilhante dos \\ oditebrilhante@hotmail.com \\ UEAP - Universidade do Estado do Amapá
}

\begin{abstract}
RESUMO $O$ artigo aborda a modalidade de ensino Educação de Jovens e Adultos (EJA). Visa analisar o perfil sociocultural e socioeducacional de mulheres egressas da EJA e os significados atribuídos quanto ao ingresso, como discentes, de uma universidade pública. Resulta de uma pesquisa etnossociológica de abordagem qualitativa. Os sujeitos são quatro mulheres discentes de uma universidade pública, egressas da EJA. Os dados foram apreendidos pela técnica denominada de entrevista narrativa, sistematizados em quadros e analisados por concepções presentes no texto, como: sujeito-educando da EJA, sonho possível e inédito viável. Entre os resultados, aponta-se para os contextos de negação da vida humana. Conclui-se que as mulheres demonstraram que é possível transformar a história.
\end{abstract}

Palavras-chave: EJA. Inédito viável. Mulheres. Perfil. Sonho possível. Universidade.

ABSTRACT This article discusses the type of education called "Youth and Adult Education" (EJA). It aims at analyzing the socio-cultural and socio-educational profile of female former students from EJA and the meanings given when they entered a public university. It consists of an ethno-sociological research of qualitative type. The subjects are four women students at a public university who are former students from EJA. Data were obtained by the narrative interview technique, systematized in tables and analyzed by concepts that are shown in the text, such as: subjects / students of EJA, realistic expectations and untested feasibility. The results point to the conditions of denial of human life. In conclusion, women have shown that it is possible to transform history.

Keywords: EJA. Untested feasibility. Women. Profile. Realistic expectations. University. 
Atos de Pesquisa em Educação - ISSN 1809-0354

Blumenau - vol. 11, n. 2, p.444-467 ago./nov. 2016

DOI: http://dx.doi.org/10.7867/1809-0354.2016v11n2p444-467

\section{INTRODUÇÃo}

O artigo tematiza intempéries, sonhos possíveis e inéditos viáveis enquanto tramas existenciais de mulheres discentes de uma universidade pública brasileira, que foram egressas da modalidade de ensino Educação de Jovens e Adultos (EJA).

O interesse por este estudo pauta-se pela escassez de pesquisas sobre a EJA. É o que conclui o estudo de Haddad (2002) sobre produções científicas que focaram a educação de adultos no período de 1986 a 1998, constatado que menos de $3 \%$ das dissertações e teses da área da Educação tiveram como objeto de estudo esta modalidade.

Esta constatação perdura. Nossa equipe de trabalho encontrou no Banco de teses da Coordenação de Aperfeiçoamento de Pessoal de Nível Superior (Capes) 7.508 registros de resumos de dissertações e teses oriundos de programas de pósgraduação em Educação. Destes, ao se aplicar como descritor de busca o termo "EJA", encontrou-se 350 registros, que representa o percentual ainda muito baixo de 4,66\% de pesquisas em nível stricto sensu da área Educação, de um país que:

[...] mantém uma dívida com 30 milhões de jovens e adultos com mais de 14 anos de idade que não sabem ler e escrever ou que apenas deram os primeiros passos nesse processo, não adquirindo habilidades suficientes para enfrentar os desafios cotidianos de uma sociedade como a nossa (HADDAD, 2011, p. 7).

Pesquisas que relacionem EJA e mulheres são ainda mais escassas. Conforme Dias, Oliveira e Mota Neto (2012), de 137 registros de dissertações e teses em Educação sobre o tema "EJA e pedagogia freireana", correspondente ao período de 1992 a 2010, duas dissertações abordaram a temática de gênero, mas apenas uma abordou sobre mulheres. "Educação de Jovens e Adultos: palavras de mulheres a respeito do processo de escolarização" é uma dissertação de mestrado datada de 2007, de autoria de Carolina Rodrigues Manzato, e teve como foco a reintegração de mulheres no meio escolar. A segunda dissertação, datada de 2010, tematiza expectativas de idosos em relação à EJA, de autoria de Jacqueline Mary Monteiro Pereira.

Por outro lado, compreende-se que a despeito de importantes estudos e pesquisas contribuírem com a caracterização do perfil dos sujeitos-educandos da EJA 
Atos de Pesquisa em Educação - ISSN 1809-0354

Blumenau - vol. 11, n. 2, p.444-467 ago./nov. 2016

DOI: http://dx.doi.org/10.7867/1809-0354.2016v11n2p444-467

-Oliveira (1999), Haddad (2002), Arroyo (2011) e Jardilino e Araújo (2014), entre muitos outros - fazem-no de maneira genérica:

Em geral, são alunos já inseridos no mercado de trabalho ou que nele ainda esperam ingressar; que não visam apenas à certificação para manter sua situação profissional, mas esperam chegar ao ensino médio ou à universidade, a fim de ascender social ou profissionalmente (JARDILINO; ARAÚJO, 2014, p. 164, grifo nosso).

Ao reconhecer-se a importância desses e outros estudos e pesquisas que apontam o perfil dos sujeitos-educandos da EJA, o presente trabalho se apresenta como um contributo à construção desse perfil, mas pontuando a especificidade do sexo feminino, haja vista que a mulher, ao longo da história, é vítima do machismo e de seus desdobramentos sociais. Não é sem motivo que "[...] a porcentagem de mulheres analfabetas é maior que a de homens" (JARDILINO; ARAÚJO, 2014, p. 167).

Nesse sentido, o artigo tem dois objetivos: traçar um perfil sociocultural e socioeducacional de mulheres egressas da EJA e discentes de uma universidade pública; e analisar as relações entre as subjetividades dessas mulheres e os condicionantes pelos quais passaram.

Para tanto, adotou-se como referencial teórico predominante o pensamento educacional de Paulo Freire, desde obras, como: Pedagogia do Oprimido, Pedagogia da Esperança, Pedagogia da Tolerância, Pedagogia dos Sonhos Possíveis, entre outras.

Metodologicamente, o artigo resulta de uma pesquisa de abordagem qualitativa do tipo etnossociológica. Compreende-se que a abordagem qualitativa:

[...] trabalha com o universo de significados, motivos, aspirações, crenças, valores e atitudes, o que corresponde a um espaço mais profundo das relações, dos processos e fenômenos que não podem ser reduzidos à operacionalização de variáveis (MINAYO, 2010, p. 21-22).

A pesquisa etnossociológica é "[...] um tipo de pesquisa empírica apoiada na pesquisa de campo e no estudo de caso" (BERTAUX, 2010, p. 23), que faz uso do método de pesquisa denominado Narrativas de Vida, que se: "constitui [em] uma descrição próxima da história 'realmente vivida' (objetiva e subjetivamente)" (p. 15) e 
Atos de Pesquisa em Educação - ISSN 1809-0354

Blumenau - vol. 11, n. 2, p.444-467 ago./nov. 2016

DOI: http://dx.doi.org/10.7867/1809-0354.2016v11n2p444-467

que valoriza os princípios do diálogo e da espontaneidade ao enfatizar o contar, o narrar.

Constituiu-se em procedimento inerente dessa pesquisa o levantamento documental exploratório que se baseou na análise de resumos de teses e dissertações de programas de pós-graduação em Educação, constantes no Banco de Teses da Capes.

Os dados disponíveis no Banco de Teses da Capes estão restritos há apenas os anos de 2011 e 2012, o que não permitiu uma análise abrangente e aprofundada. Tendo-se como descritores de busca, o termo: "EJA", foram encontrados 350 resumos. Ao adotar o descritor "EJA e mulheres", a quantidade de registro decresceu para 11 (onze), apenas. Destes, nenhum aponta para o mesmo foco deste artigo: mulheres egressas da EJA que conquistaram uma vaga em graduação de uma universidade pública brasileira.

Ressalta-se um agravante: o Banco de Teses da Capes constitui-se no mais importante repositório nacional de teses e dissertações de programas de pósgraduação, reconhecidos pelo Ministério da Educação.

Também foi realizado um levantamento bibliográfico de livros e artigos científicos com vistas a formular uma compreensão acerca de conceitos centrais a esse artigo, como: intempéries; sonhos possíveis; inédito viável, educação de jovens e adultos; e sujeito-educando da EJA.

Os sujeitos da pesquisa foram quatro mulheres egressas da EJA, todas discentes do Curso de Licenciatura em Pedagogia, situado no Campus 2 da Universidade do Estado do Amapá. Essa graduação apresenta apenas quatro turmas, sendo que cada mulher sujeito da pesquisa foi oriunda de uma dessas turmas. Para preservar suas identidades, optou-se pela utilização dos seguintes pseudônimos: Maria, Antônia, Francisca e Paula.

Como técnica de apreensão dos dados de campo utilizou-se a entrevista narrativa: "durante a qual um 'pesquisador' (que pode ser um estudante) pede a uma pessoa, então denominada 'sujeito', que the conte toda ou uma parte de sua experiência vivida" (BERTAUX, 2010, p. 15).

Em momento que antecedeu as entrevistas narrativas, cada sujeito da pesquisa leu e assinou um Termo de Consentimento Livre e Esclarecido. Em seguida, foram 
Atos de Pesquisa em Educação - ISSN 1809-0354

Blumenau - vol. 11, n. 2, p.444-467 ago./nov. 2016

DOI: http://dx.doi.org/10.7867/1809-0354.2016v11n2p444-467

realizadas quatro entrevistas narrativas com auxílio de gravador de voz, que foram transcritas e sistematizadas em quadros analíticos elaborados em editor de texto. Em seguida, os dados foram agrupados em categorias temáticas, entre as quais, destacam-se: perfil sociocultural e perfil socioeducacional.

Além dessa Introdução, o corpus do artigo aborda conceitos freireanos centrais à análise do objeto de estudo, desenvolve uma concepção de educação de jovens e adultos e de sujeitos-educandos dessa modalidade em uma perspectiva críticolibertadora. Em seguida, analisam-se os perfis socioculturais e socioeducacionais das mulheres sujeitos da pesquisa, tendo como foco suas intempéries, sonhos possíveis e inéditos viáveis. Por fim, aponta-se a carência generalizada do poder público em relação à promoção da educação pública, gratuita e de qualidade. As mulheres atribuíram status de inédito viável à conquista de uma vaga na universidade pública, que se desdobra em um sentimento de realização, devido à superação de condicionantes sociais e econômicos que historicamente deixam as mulheres à margem da educação escolar no Brasil.

\section{CONCEITOS CENTRAIS}

Compreende-se a intempérie no sentido metafórico, isto é, como condições adversas, circunstâncias infelizes, desgraças (FARIA, 2003) que está sujeito o ser humano enquanto ser existente no e com o mundo. Para este artigo, a intempérie refere-se às condições adversas enfrentadas por mulheres egressas da EJA e que ingressaram como discentes de uma universidade pública brasileira.

Os conceitos sonho possível e inédito viável são oriundos do pensamento educacional de Paulo Freire e foram devidamente catalogados por Streck, Redin e Zitkoski (2008) em uma produção técnica denominada "Dicionário Paulo Freire". A seguir, aborda-se uma compreensão sobre esses dois conceitos, recorrendo-se às concepções freireanas de ser humano e de história.

Na perspectiva de Paulo Freire ${ }^{1}$, o ser humano é compreendido como corpo consciente, isto é: "consciência intencionada ao mundo, à realidade" (FREIRE, 1985,

\footnotetext{
${ }^{1}$ Paulo Freire elaborou sua concepção de ser humano e construiu seu pensamento educacional com influência de diferentes correntes filosóficas, como a Fenomenologia, o Existencialismo Cristão e o Marxismo (OLIVEIRA, 2011).
} 
Atos de Pesquisa em Educação - ISSN 1809-0354

Blumenau - vol. 11, n. 2, p.444-467 ago./nov. 2016

DOI: http://dx.doi.org/10.7867/1809-0354.2016v11n2p444-467

p. 66), que atua, pensa e se comunica sobre esta realidade com outros seres humanos; que nela intervém, transforma-a e é por ela transformado.

A transformação é o mote existencial pelo qual o ser humano é compreendido em permanente processo de se fazer: o ser humano não é, está sendo. Nesse sentido, a história em perspectiva freireana é compreendida como inerência humanada possibilidade de transformação, inclusive das conjunturas sociais. Motivo pelo qual Freire (2002, p. 36) afirma: "Mulheres e homens, seres histórico-sociais, nos tornamos capazes de comparar, de valorar, de intervir, de escolher, de decidir, de romper, por tudo isso nos fizemos seres éticos. Só estamos porque estamos sendo".

Freire se posiciona contra a concepção imobilizadora de história, vista como dado fixo, imutável, poisreduz o ser humano à condição da adaptação. Tal concepção de história diz respeito à politicidade enquanto interesses de classes, grupos, nações e sistemas, que, no contexto capitalista, reforça uma ideologia fatalista "[...] que estimula a imobilidade dos oprimidos e sua acomodação à realidade injusta, necessária ao movimento dos dominadores" (FREIRE, 2000, p. 13).

Nas palavras de Freire (2002, p. 21, destaque do autor), tendo-se como opção os oprimidos, os excluídos, as vítimas do sistema, é preciso: "Reconhecer que a História é tempo de possibilidade e não de determinismo, que o futuro permita-se-me reiterar, é problemático e não inexorável".

Ante à concepção de ser humano e de história em perspectiva freireana, as intempéries sociais, políticas, econômicas, culturais, etc., por que passa alguém, toda uma comunidade ou uma sociedade mais ampla são compreendidas não como dados inexoráveis, mas como condicionantes possíveis de serem transformados.

Sendo a realidade sócio-histórica, portanto, viável de ser transformada, é um imperativo de esperança sonhar o possível, isto é, o que ainda não aconteceu. Esse sonho freireana surge da realidade material circundante e não de suposições deslocadas dos contextos sócio históricos em que sujeitos se fazem e se refazem. Eis a razão de Freire (2004, p. 293) afirmar que: "sonhar aí não significa sonhar a impossibilidade, mas significa projetar. Significa arquiteturar, significa conjecturar sobre o amanhã".

Os sonhos possíveis constituem-se na gênese da utopia de um amanhã melhor, que se traduz na luta esperançosa de um futuro de humanização e de 
Atos de Pesquisa em Educação - ISSN 1809-0354

Blumenau - vol. 11, n. 2, p.444-467 ago./nov. 2016

DOI: http://dx.doi.org/10.7867/1809-0354.2016v11n2p444-467

libertação. Enquanto luta, é um primeiro nível de mobilização para a mudança que ocorre dialeticamente em plano pessoal-coletivo, mas também por meio do par denúncia-anúncio.

Não é possível compreender o conceito de inédito viável sem o auxílio relacional e orgânico da categoria sonho possível, pois é um potente mobilizador da ação processual visando sua materialização. Nesse sentido, o inédito viável é práxis que se faz na história como possibilidade em busca da realização do sonho possível. É a ação praxeológica de tornar possível o dito como impossível, em um dado contexto sócio-histórico. Assim, nas palavras de Freire (2008, p. 233):

O inédito viável é na realidade, pois, uma coisa que era inédita, ainda não claramente conhecida e vivida, mas quando se torna um 'percebido destacado' pelos que pensam utopicamente, o problema não é mais um sonho, ele pode se tornar realidade.

Cabe destacar que o inédito viável é potencialmente gerador de novos sonhos possíveis.Um exemplo notório foi o sonho de Freire em construir uma escola pública democrática e popular quando foi Secretário de Educação do Município de São Paulo (1989-1991), pois, a despeito de dificuldades de diversas ordens, conseguiu concretizar um projeto de "mudança da cara da escola" (FREIRE, 2005). Eis um inédito viável que despertou o sonho possível de muitas outras administrações públicas educacionais. Motivo pelo qual a Gestão Freire veio a se tornar referência às políticas educacionais de inúmeros estados e municípios brasileiros, conforme apontam Saul e Silva (2009, p. 228, grifo nosso):

\footnotetext{
A partir de 1992, vários Estados e municípios brasileiros comprometidos com a administração popular optaram por construir políticas curriculares com os pressupostos freireanos do Movimento de Reorientação Curricular ocorrido em São Paulo (gestão 1989-1992). Dentre eles, destacaram-se: Angra dos Reis-RJ (1994-2000); Porto Alegre-RS (1995-2000); Chapecó-SC (19982003); Caxias do Sul-RS (1998-2003); Gravataí-RS (1997-1999); Vitória da Conquista-BA (1998-2000); São Paulo-SP (2001-2003); Belém-PA [19972004]; Maceió-AL (2000-2003); Dourados-MS (2001-2003); Goiânia-GO (2001-2003); Criciúma-SC (2001-2003); Rio Grande do Sul (1998-2001); Alagoas (2001-2003).
}

Assim, sonhos possíveis e inéditos viáveis são categorias que se reforçam mutuamente. Conceitualmente, uma contribui para explicar a outra porque têm como 
Atos de Pesquisa em Educação - ISSN 1809-0354

Blumenau - vol. 11, n. 2, p.444-467 ago./nov. 2016

DOI: http://dx.doi.org/10.7867/1809-0354.2016v11n2p444-467

matriz comum a concepção de ser humano enquanto ser de abertura e a compreensão de história como possibilidade.

Compreende-se educação de jovens e adultos tendo-se como referência a base legal nacional e produções científicas ancoradas em uma perspectiva humanista-libertadora de educação, oriunda da educação popular freireana e da Ética da Libertação de Enrique Dussel.

Legalmente, a educação escolar no Brasil é direito de todos, constituindo-se em dever do Estado e da família (BRASIL, 1988), sendo a Educação de Jovens e Adultos (EJA) uma modalidade de ensino da Educação Básica (BRASIL, 1996), com diretrizes operacionais próprias (BRASIL, 2010).

Embora se reconheçam os avanços políticos e sociais ocasionados pela legislação brasileira à educação escolar e à EJA, é preciso compreender esta modalidade como frente de libertação, o que implica em alguns reconhecimentos: que em termos gerais os jovens, adultos e idosos que procuram a EJA na qualidade de sujeitos-educandos são sujeitos vitimizados pela sociedade; que o sistema educacional é elitista; que é preciso pensar em ações factíveis de mudanças deste contexto educacional, o que pressupõe intervenção na realidade promovendo mudanças na história em favor dos sujeitos excluídos (DIAS, 2015).

À EJA como frente de libertação, elencam-se ainda outros cinco campos identitários, conforme as contribuições de Arroyo (2011), quais sejam: pesquisa; políticas públicas; formação de educadores, produção teórica e de intervenções pedagógicas.

Além de se constituir como um campo de pesquisas e de formação, a EJA vem encontrando condições favoráveis para se configurar como um campo específico de políticas públicas, de formação de educadores, de produção teórica e de intervenções pedagógicas.

Ante a esta perspectiva ampliada de EJA, estes campos apontados por Arroyo (2011) constituem-se também em frentes de libertação na medida em que trazem consigo a potencialidade libertadora das ações pedagógicas a serem realizadas como sujeito-educando da EJA.

Compreende-se 0 sujeito-educando da EJA não apenas desde o reconhecimento de sua materialidade negada apontada como desumanização. Para 
Atos de Pesquisa em Educação - ISSN 1809-0354

Blumenau - vol. 11, n. 2, p.444-467 ago./nov. 2016

DOI: http://dx.doi.org/10.7867/1809-0354.2016v11n2p444-467

além do reconhecimento concreto da desumanização, todo sujeito excluído e oprimido - inclusive se este se tratar do sujeito-educando da EJA - possui o gérmen ontológicohistórico da libertação das realidades excludentes e opressoras, a ocorrer nos planos individual e comunitário.

É o que Freire (2014, p. 41) apontou como vocação ontológica do ser mais, que na história se faz como "luta pela humanização, pelo trabalho livre, pela desalienação, pela afirmação dos homens e mulheres como pessoas, como seres para si".

Portanto, adota-se uma concepção de ser humano que frequenta a EJA como estudante nos seguintes termos: em primeiro lugar como sujeito humano, como educando de um sistema educacional escolar nacional, como vítima de uma dada realidade sócio-histórica, mas com potencial histórico-ontológico de libertação. De fato: "os educandos da EJA não são os pobres, os índios, os migrantes, toda sorte de grupos sociais excluídos, mas sim: sujeitos-educandos-vítimas-em processo de libertação" (DIAS, 2015, p. 168, grifo nosso).

Em síntese, este sujeito-educando situa-se em uma concepção de EJA que, ocupada com a transformação de realidades desumanizantes:

Seja cada vez mais reconhecida como modalidade de ensino, mas tenha relativa autonomia burocrático-pedagógica a ponto de manter-se sempre sensível às realidades dos sujeitos sociais que historicamente se constituem em seus principais educandos - as vítimas do sistema, os excluídos da globalização (DIAS, 2015, p. 170).

Assim, reconhece-se, a necessidade de se estar sensível às especificidades dos sujeitos-educandos que historicamente encontram nesta modalidade de ensino (mais) uma chance de (re)começar os estudos em ambientes escolares, haja vista que de maneira geral constituem-se em vítimas da exclusão, opressão e negação em uma sociedade capitalista que reifica quem não se enquadra ao perfil de sujeito consumista capaz de contribuir plenamente com a manutenção do sistema econômico vigente.

\section{PERFIL SOCIOCULTURAL E SOCIOEDUCACIONAL DE MULHERES EGRESSAS DA EJA}


Atos de Pesquisa em Educação - ISSN 1809-0354

Blumenau - vol. 11, n. 2, p.444-467 ago./nov. 2016

DOI: http://dx.doi.org/10.7867/1809-0354.2016v11n2p444-467

A opção em adotar como sujeitos da pesquisa mulheres egressas da EJA, discentes de um curso de graduação de uma universidade pública brasileira, deve-se ao fato de que em termos gerais, vive-se paradoxalmente em um sistema-mundo que se constitui pretensamente globalizador, mas, na medida em que se situa pelos quadrantes do planeta, gera quantidades cada vez maiores de marginalizados sociais, de classe e negados em sua materialidade, quer sejam pessoas ou grupos. Entre estes sujeitos negados, excluídos encontram-se as mulheres (DUSSEL, 2012).

Esse panorama apontado por Dussel (2012) também se faz presente no Brasil. De fato, este é o motivo pelo qual Lima, Stecanela e Poletto (2014, p. 07-08) afirmam que: "Somente nos últimos trinta anos que a mulher vem se beneficiando da lenta expansão e democratização do acesso à escola, que se principiou nas camadas da alta sociedade".

Para formular o perfil sociocultural dos sujeitos da pesquisa levou-se em consideração suas idades de vida quando concluíram a EJA e de quando ingressaram na universidade. Considerou-se também suas origens em relação ao país, unidade da federação, município, zona de residência (rural ou urbana), escolaridade dos pais, séries/etapas que cursou na EJA e relações entre educação e trabalho.

Primeiramente, optou-se em conhecer os sujeitos da pesquisa antes de sua inserção na EJA e na educação superior. A respeito disso, Antônia aponta:

"Minha família ficava de um interior para o outro, em busca de melhores condições [...] fiquei sem estudar, durante o período de 01 ano, e aí ficava difícil [...] mas eu sempre tive vontade de estudar, tanto que eu estou aqui agora".

Constatou-se que a idade de conclusão da educação básica das mulheres entrevistadas varia entre 20 a 26 anos. Faixa etária condizente com as Diretrizes Operacionais para a Educação de Jovens e Adultos:

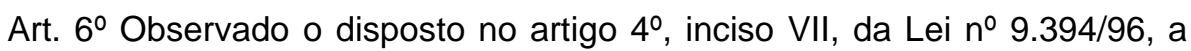
idade mínima para matrícula em cursos de EJA de Ensino Médio e inscrição e realização de exames de conclusão de EJA do Ensino Médio é 18 (dezoito) anos completos (BRASIL, 2010, p. 02).

Outro dado que chama a atenção é que embora atualmente as entrevistadas residam no Estado do Amapá, constata-se que duas delas residiam em zonas rurais do Estado do Pará, durante o período em que cursaram a EJA. Aponta-se, assim, o 
Atos de Pesquisa em Educação - ISSN 1809-0354

Blumenau - vol. 11, n. 2, p.444-467 ago./nov. 2016

DOI: http://dx.doi.org/10.7867/1809-0354.2016v11n2p444-467

perfil de sujeitos migrantes, conforme narrativa a seguir: "Eu morava no interior do Pará, morei em vários na verdade por lá, como minha mãe e meu padrasto mexia com essas questões de terras, então aonde tinha oportunidade a gente estava indo" (ANTÔNIA).

Este depoimento corrobora o ponto de vista de Oliveira (1999, p. 59) ao explicitar que o sujeito da EJA "é geralmente o migrante que chega às grandes metrópoles proveniente de áreas rurais empobrecidas". Não que o Estado do Amapá seja uma metrópole, mas se comparado às localidades em que residiam, é provável que tenha melhores condições de trabalho e acesso à educação escolar, inclusive de nível superior.

Outro traço do perfil sociocultural dos sujeitos da pesquisa está na constatação de que os pais de todas elas possuíam baixo nível de escolaridade quando estas cursaram a EJA:

"Ensino fundamental incompleto, tanto a mãe quanto o pai até a $4^{\circ}$ série" (MARIA).

"A minha mãe terminou o 2ํgrau e o meu pai estudou até a 4º série do Ensino Fundamental" (ANTÔNIA).

"Eles não estudaram na EJA, os dois, se não me engano pararam na 6o ou 7ํ sério eu acho" (FRANCISCA).

"Meu pai, acho que 4⿳亠丷厂 série, e a minha mãe, ela não tinha escolaridade" (PAULA).

Oliveira (1999, p. 59) também menciona que o sujeito da EJA, comumente é "filho de trabalhadores rurais não qualificados e com baixo nível de instrução escolar", a partir dessa informação deduz-se que o histórico socioeducacional dos pais destes sujeitos reflete diretamente em sua formação.

Quando indagadas sobre as séries/etapas que cursaram na EJA, obteve-se os seguintes dados: "10, $2^{\circ}$ e $3^{\circ}$ ano, todo ensino médio eu cursei na EJA" (MARIA); "Eu ingressei na EJA e conclui meu ensino médio em 02 anos na Escola Sagrado Coração de Jesus, terminei em 2007" (ANTÔNIA); "Eu fiz a $7^{a}$ e a $8^{a}$ e fiz o $2^{\circ}$ e $3^{\circ}$ que foi o ano passado agora, 2014" (FRANCISCA); e "20 e $3^{\circ}$ ano" (PAULA). 
Atos de Pesquisa em Educação - ISSN 1809-0354

Blumenau - vol. 11, n. 2, p.444-467 ago./nov. 2016

DOI: http://dx.doi.org/10.7867/1809-0354.2016v11n2p444-467

Percebeu-se que a passagem desses sujeitos pela EJA deu-se de forma rápida e em diferentes etapas desta modalidade. Procura esta, que advém de uma lacuna no percurso educacional destes sujeitos.

Considerou-se relevante conversar com as entrevistadas sobre quais atividades laborais exerceram concomitante à EJA. Além disso, investigou-se a razão pela qual trabalhavam. Obteve-se os seguintes registros:

"Eu trabalhava como vendedora na época em uma loja, no centro comercial [...] era necessário porque tenho filho e mantinha a casa, eu era responsável pela criação dele" (MARIA).

"Na época eu era autônoma, trabalhava em lanchonete [...] trabalhei todo o período que eu estive cursando o ensino médio. Trabalhei e estudei"! (ANTÔNIA).

"Eu vivia de comércio [...] só meu esposo trabalhava, para mim era incômodo ficar só em casa, como minha família precisava de mim na época para tomar conta dos negócios, preferi trabalhar" (PAULA).

A partir do relato de Maria, percebe-se que sua historicidade se enquadra em um contexto da EJA de mulheres que: "lutam pela sua sobrevivência e a de seus filhos, [...] ou mesmo de busca por melhores condições de vida" (MARCARINI; MÉNDEZ 2014, p. 335).

Neste sentido, as mulheres que estudam na EJA, em sua maioria já estão inseridas no mercado de trabalho e precisam conciliar emprego e estudos, na busca por qualificação profissional que implique em melhorias para si e seus dependentes.

Para a elaboração do perfil socioeducacional utilizou-se os seguintes eixos orientadores: itinerário educacional na EJA; oferta da educação e o papel do Estado; e perspectiva de futuro quando cursava a EJA.

Primeiramente, confere-se destaque para os motivos que levaram as quatro mulheres, sujeitos da pesquisa, a ingressar na Educação de Jovens e Adultos:

"Pelo fato de ser bem mais rápido, e porque eu não pude concluir na idade considerada adequada, por já está atrasada, eu necessitava de um certificado de conclusão do ensino médio, a EJA, pelo fato, de ser à noite e eu trabalhava, foi o caminho mais fácil para que eu alcançasse o objetivo, que era o diploma de conclusão do ensino médio" (MARIA).

"Primeiro porque eu estava muita atrasada! Eu precisava terminar meu ensino médio, porque eu trabalhava durante o dia e eu só tinha o horário da noite para estudar. Eu já estava numa idade avançada, já tinha minha primeira filha, 
Atos de Pesquisa em Educação - ISSN 1809-0354

Blumenau - vol. 11, n. 2, p.444-467 ago./nov. 2016

DOI: http://dx.doi.org/10.7867/1809-0354.2016v11n2p444-467

inclusive eu a levava. Ela passou os 02 anos indo comigo e aí era a forma mais fácil de terminar o ensino médio" (ANTÔNIA).

"Eu perdi minha visão com 13 anos, parei na $6^{\circ}$ série, eu tive que viajar para fazer meu tratamento [...] depois continuei [...] fiz $7^{\circ}$ e $8^{\circ}$ na $E J A,[. ..] 2^{\circ}$ e $3^{\circ}$ foi na EJA também [...] fiz a EJA para terminar mais rápido" (FRANCISCA).

"Precisaria do nível superior para ser professora, achava que se eu fizesse regular ia demorar mais, pela minha idade. Então eu optei pela EJA, porque diminuiria o tempo e eu alcançaria o que eu queria realmente em menos tempo, cursando a EJA" (PAULA).

Percebe-se um motivo comum que as levou a cursar a EJA: a significativa agilidade na conclusão das séries/etapas que não puderam cursar durante a infância e adolescência. Todavia, as entrelinhas das narrativas revelam uma das faces da exclusão e discriminação existente em nossa sociedade, uma vez que a educação escolar enquanto direito foi-lhes negado desde sua infância, por falta de condições estruturais e financeiras do sistema educacional. Mais que isso, por faltar escolas que ofertem educação escolar pública de qualidade. Essa situação evidencia-se no registro a seguir:

Quando eu morei no interior, o "teto" das séries era até a 5a série, quando chegava a quinta série tinha que voltar, se não ficava sem estudar [...] Comigo aconteceu isso. Comecei tudo novamente! $1^{a}, 2^{a}, 3^{a}$ série, por isso tive esse atraso nos meus estudos (ANTÔNIA).

Situação que se torna mais evidente com os excertos a seguir, quando abordadas sobre o papel do Estado na educação pública:

Uma educação escolar ínfima, porque o que se tinha de metodologia, e material disponível na época nessa localidade era muito precário. Resumia-se a um caderno, um lápis e uma caneta e raramente tínhamos acesso à livros. Nós aprendemos basicamente apenas a escrever, as quatro operações básicas do cálculo matemático. História nunca estudamos, foi basicamente Português e Matemática (MARIA).

Eu acho que o Estado deveria investir mais na EJA, tanto na questão de colocar mais professores, quanto na divulgação e na oferta. Na época eram poucas as escolas que eu estudava e logo após reduziu mais ainda. Não tinha muitas escolas, tinha que andar um bom pedaço para chegar à escola, e era muito difícil! (ANTÔNIA)

Na minha opinião, o que o Estado está fazendo é apenas ofertar as vagas, mas não garante a permanência do educando, por exemplo, quando fiz a matrícula 
Atos de Pesquisa em Educação - ISSN 1809-0354

Blumenau - vol. 11, n. 2, p.444-467 ago./nov. 2016

DOI: http://dx.doi.org/10.7867/1809-0354.2016v11n2p444-467

tinha muitas vagas, tanto é que quando passou o período da matrícula, você poderia procurar que ainda tinha vagas (PAULA).

Neste contexto, aponta-se a realidade de descaso na qualidade da educação oferecida, na quantidade de escolas insuficientes, principalmente em se tratando de zonas rurais, bem como a falta de políticas e práticas pedagógicas de permanência do educando da EJA.

Defende-se a ideia do quanto essa modalidade de educação precisa ser repensada no sentido de não se restringir à oferta, mas também à permanência destes sujeitos-educandos nas unidades escolares e nos locais onde vivem.

De fato, a questão do acesso e permanência aos processos educacionais escolares, transcende a dimensão da escola. É preciso considerar em termos macrossociais os territórios em que estes sujeitos se produzem socioculturalmente, bem como as condições para se manterem economicamente e, em relação à educação, considerar propostas político-educacionais que respeitem as especificidades dos sujeitos-educandos. Observe-se que em dados anteriores analisados, percebeu-se como perfil de sujeito-educando da EJA, a mulher migrante, fazendo a rota CAMPO-CIDADE.

Para compor o presente perfil tornou-se relevante obter informações sobre suas perspectivas de futuro enquanto cursaram a EJA:

"Eu sonhava para o meu futuro, primeiramente um emprego melhor, que me proporcionasse uma renda maior, para que eu pudesse ter uma melhor qualidade de vida, não somente para mim, mas para que eu pudesse proporcionar para meu filho também, este era o sonho, o principal que eu tinha enquanto eu estudava na EJA" (MARIA).

"Minha professora de atendimento educacional especial me dava muita força de vontade, eu nunca tive vontade de desistir, de parar de estudar, e eu tive os meus sonhos de cursar uma faculdade, ter um emprego, e assim, cuidar da minha família, dar um apoio financeiro para minha mãe, ajudar minhas irmãs" (FRANCISCA).

"Quando entrei na EJA, já tinha um papel bem definido do que eu realmente queria, era o Ensino Superior" (PAULA).

Estas narrativas demonstram que mesmo com todos os problemas que cercam a referida modalidade, a EJA tem contribuído para a superação da exclusão social, oportunizando que seus sujeitos-educandos deem continuidade aos estudos. 
Atos de Pesquisa em Educação - ISSN 1809-0354

Blumenau - vol. 11, n. 2, p.444-467 ago./nov. 2016

DOI: http://dx.doi.org/10.7867/1809-0354.2016v11n2p444-467

Observa-se que estes sujeitos-educandos representam a educação escolar como esperança de melhorias de vida, transfigurada na possibilidade de ascensão social. Representação que reforça a sobrevalorização de saberes letrados em uma sociedade majoritariamente letrada: "A questão de querer ter uma vida melhor, de saber que isso só seria possível através dos estudos, só seria possível ter uma vida mais confortável, ter uma renda um pouco melhor, somente se eu estudasse" (MARIA).

A respeito disso, Bernardim (2013, p. 215) indica:

Na modalidade EJA permanece forte a percepção de que a educação pode contribuir não só para a melhoria das condições de trabalho e renda, como para a obtenção de emprego. Essa perspectiva também tem se ampliado entre aqueles que, tendo concluído o Ensino Médio há mais tempo, percebem o nível superior como importante para melhorar sua condição de inserção socioeconômica. Assim, almejaram chegar à educação superior com a perspectiva de melhorar suas condições materiais de vida, passando a valorizar cada vez mais a universidade como meio ascensão e inclusão social.

Assim, considera-se que as mulheres, sujeitos da pesquisa, almejaram chegar à educação superior com a perspectiva de melhorar suas condições materiais de vida, passando a valorizar cada vez mais a universidade como meio de inclusão e ascensão social.

\section{CONCRETIZAÇÃO DE INÉDITOS VIÁVEIS: DA EJA À UNIVERSIDADE}

Dois eixos narrativos contribuíram para a construção dessa seção: (1) Conte como foi para você conquistar uma vaga na educação superior; (2) Narre sua perspectiva de futuro quando concluir o curso de graduação.

No primeiro eixo narrativo, buscou-se compreender o significado que as mulheres universitárias egressas da EJA atribuíram à conquista de uma vaga na educação superior. A respeito disso, as entrevistadas narram o sentimento que tiveram ao saber que haviam conquistado uma vaga na universidade pública:

"Foi emocionante! Porque eu estava há mais de 10 anos sem estudar, quando vi que o resultado do ENEM tinha sido muito bom, e minha redação tinha sido 
Atos de Pesquisa em Educação - ISSN 1809-0354

Blumenau - vol. 11, n. 2, p.444-467 ago./nov. 2016

DOI: http://dx.doi.org/10.7867/1809-0354.2016v11n2p444-467

excelente, para quem estava tanto tempo sem estudar, foi maravilhoso! Foi uma emoção indescritível!" (MARIA).

"Quando eu conquistei essa vaga, eu fiquei muito feliz! E também pude provar para muita gente que é possível sim a gente conquistar uma vaga no Ensino Superior, mesmo a gente tendo uma idade que não está no padrão. Então, eu fiquei muito feliz com essa conquista, foi o "pontapé" inicial para as coisas que eu tanto almejo para minha vida, foi o primeiro passo para as conquistas que eu vou ter futuramente" (PAULA).

Ambas as narrativas expressam de forma muito marcante o sentimento de realização. As mulheres tinham seus sonhos quase perdidos (mas não esquecidos), como o de fazer um curso superior, e, com a conquista de uma vaga na universidade pública, nasce a esperança de "mudar de vida".

Quanto a isso, Maria narra: "A partir daí eu vi, percebi que aquilo que estava dentro de mim, o sonho, a determinação, o desejo de alcançar o melhor, era possível. Eu consegui concretizar aquilo que era só um sonho, só um pensamento". Em consonância com esse depoimento, o inédito viável freireano enquanto um sonho possível está ligado justamente a essa convicção, de que as situações que pareciam imutáveis, possam, sim, ser transformadas.

Diante disso, Freire (1992, p.91) afirma que "não há mudança sem sonho, como não há sonho sem esperança". Percebe-se assim, que essas mulheres passaram a acreditar e a valorizar cada vez mais a universidade, como meio para sua inclusão social. Perceberam o alargamento das possibilidades, na esperança de concretizar um inédito viável em um futuro próximo, por meio da educação de nível superior.

A esse respeito, Marcarini e Méndez (2014, p. 349) afirmam que: "[...] a educação tem papel importante na vida dessas mulheres, pois representa dois movimentos de resistência: primeiro ao determinismo da vida das mulheres em face do patriarcado; segundo, ao acesso a novos horizontes, novas possibilidades".

Nesse sentido - ao considerar que a representação social negativa de que em geral os sujeitos-educandos da EJA são pessoas desacreditadas por si próprias e pela sociedade - Francisca se apresenta como exemplo de resistência e de superação para sua família e para a sociedade, pois aponta: "Eu não sei como explicar, acho que sou um exemplo para a sociedade, não só para sociedade, mas para minha família". Cabe destacar que a narradora é uma mulher que perdeu a visão aos 13 anos. 
Atos de Pesquisa em Educação - ISSN 1809-0354

Blumenau - vol. 11, n. 2, p.444-467 ago./nov. 2016

DOI: http://dx.doi.org/10.7867/1809-0354.2016v11n2p444-467

Geralmente, e infelizmente, os alunos da EJA se sentem inferiores aos alunos que tiveram acesso à educação escolar desde a infância. Depreende-se que, se estas mulheres tenham apresentado este sofrimento ético-político, não deixaram se levar por este sentimento de inferioridade, pois não deixaram que as dificuldades se tornassem fatores determinantes para que suas existências se tornassem apenas determinismo fatalista. Pelo contrário, acreditaram no poder de superação, na realização de um inédito viável em suas vidas. Dessa forma, Maria aponta:

Eu sei que era muito concorrido, entre uma pessoa que já está há mais de 10 anos sem estudar e um jovem que está saindo hoje do ensino médio, claro que ele tinha mais possibilidade do que eu. Mas eu percebi com isso que é possível, que se você se colocar, se você buscar não importa o tanto de concorrente que você tem, você tem que se colocar para você ter a chance.

Por fim, nas narrativas, evidencia-se a presença da categoria freireana esperança, que está ligada ao inédito viável ou sonho possível. De acordo com Freire (2014, p. 97), "não é, porém, a esperança um cruzar de braços e esperar. Movo-me na esperança enquanto luto e se luto com esperança, espero". Para corroborar esse pensamento de Freire, Maria aponta: "se apenas ficar imaginando e não sair em busca daquilo que você quer, você não vai sair de onde está, você precisa ir além".

No segundo eixo narrativo, buscou-se conhecer a perspectiva de futuro das acadêmicas após conclusão do curso de graduação. Evidencia-se a unanimidade em relação à vontade de seguir estudando e pôr em prática o aprendizado adquirido durante a graduação:

Com certeza é continuar estudando, fazer pós-graduação e assim, eu ainda não escolhi, ainda não sei ao certo se quero atuar na educação infantil ou na coordenação pedagógica, o certo é que pretendo continuar (ANTÔNIA).

Eu quero concluir esse curso se Deus quiser, eu quero trabalhar na minha área, na área de educação especial (FRANCISCA).

As minhas perspectivas são as melhores possíveis, eu não quero parar de estudar, tudo que eu aprendi durante esses quatro anos dentro da Universidade, quero levar para dentro da escola do qual eu vou atuar (PAULA).

Depois de formada quero fazer pós-graduação. A princípio eu pretendo trabalhar na EJA, pode ser que mude essa perspectiva porque nós sabemos que não estamos prontos, estamos sempre em processo de aprendizagem, de mudança, e por esse motivo, daqui a quatro anos eu me vejo assim, trabalhando como Pedagoga, pode ser numa escola, mas pode ser em uma instituição não escolar, poder ser também em um hospital, são situações que eu não considero fechadas (MARIA). 
As entrevistadas fazem parte de um grupo que por meio de suas lutas, sonhos, objetivos e, sobretudo conquistas, tornam-se exemplos para jovens, adultos e idosos que desejam cursar a Educação Superior, mas estão desestimulados por conta do tempo que passaram sem estudar, por pensarem que não têm mais idade para entrar em uma Universidade, além de motivos que envolvem diversos fatores.

Essas mulheres encontraram na EJA uma forma de desconstruir a ideologia fatalista do: nada mais se pode fazer, ao mesmo tempo em que construíram sonhos e alcançaram inéditos viáveis. De acordo com Lima, Stecanela e Poletto (2014, p. 367) "a EJA traz novas perspectivas para jovens e adultos que desejam gozar de oportunidades". Além disso, "as mulheres fazem parte do conjunto destes atores sociais".

Assim como um dia a possibilidade de ingressar na educação superior consistia em um sonho para essas mulheres, existe um universo de alunos da EJA que compartilham desse mesmo sonho. Desta forma, compartilhando do pensamento de Freire (2005, p. 126) acredita-se que: "uma das tarefas políticas que devemos assumir é viabilizar os sonhos que parecem impossíveis".

Compreende-se que as entrevistadas estão "fazendo-se e refazendo-se no processo de fazer a história, [...] virando seres de inserção no mundo e não da pura adaptação ao mundo, terminaram por ter no sonho também um motor da história" (FREIRE, 1992 p. 91). Como revela Paula: "geralmente quando estou conversando com pessoas da minha família, com os meus amigos, eles falam que eu sou muito sonhadora".

O que iniciou com um sonho, sustentou-se de esperança, confiança e coragem para materializar-se, pois "[...] não há amanhã sem projeto, sem sonho, sem utopia, sem esperança, sem o trabalho de criação e desenvolvimento de possibilidades que viabilizem sua concretização" (FREIRE, 2001, p. 86).

Acredita-se no "discurso em favor do sonho, da utopia, da liberdade, da democracia [...] o discurso de quem recusa a acomodação e não deixa morrer em si o gosto de ser gente, que o fatalismo deteriora" (FREIRE, 2001, p. 86).

\subsection{RELATOS AOS EDUCANDOS DA EJA}


Atos de Pesquisa em Educação - ISSN 1809-0354

Blumenau - vol. 11, n. 2, p.444-467 ago./nov. 2016

DOI: http://dx.doi.org/10.7867/1809-0354.2016v11n2p444-467

Esta seção é de caráter reflexivo. Apontam-se relatos permeados de medo e ousadia, desesperanças e esperanças. Julga-se melhor não os analisar de maneira direcionada pela autoria do presente texto. Espera-se que cada leitor e leitora possa realizar as leituras das mensagens de acordo com o mundo que os mediatiza, extraindo assim os significados que melhor lhe diz respeito.

A minha mensagem para o aluno da EJA, aquele que já chegou, ou que chegou agora, ou está concluindo, é que muitas coisas independem de você, existem fatores externos que estão além das suas possibilidades, mas, a mais importante delas com certeza depende de você. Se você for determinado, se você não se deixar vencer pelas circunstâncias, pelo cansaço de quem trabalha, e chega já cansado para estudar a noite, é difícil? É, mas nessa vida nada é fácil, se você ficar acomodado, esperando que as coisas mudem sem que você faça algo para que elas mudem, esqueça porque isso não vai acontecer. Mesmo cansado estude, mesmo cansado vá para sala de aula, mesmo cansado faça os seus trabalhos, mesmo cansado olhe para sua situação atual e diga: daqui há 10 anos como eu quero me ver? Nessa mesma situação, ou ainda pior? Ou eu quero estar em um patamar diferente? Eu quero ter conquistado outras coisas? As conquistas da nossa vida elas só acontecem quando nós determinamos que vamos vencer a diversidade, a falta de recurso, as condições financeiras, a falta de recurso para que você compre aquele material que você precisa. Faça! Peça ajuda! Quando você não puder sozinho peça ajuda, com certeza vai ter um ou dois colegas que vão se disponibilizar, não tenha vergonha de falar que você não sabe, não tenha vergonha de pedir para que o professor explique a parte, não tenha vergonha de reconhecer que você tem limitações, mas que você quer vencer, e coloque no seu coração que você vai vencer, você é capaz com todas as suas limitações, você pode sim chegar aonde você almeja (MARIA).

Não importa a idade, é o que eu dizia para os meus colegas, enquanto viver a gente pode está realizando nossos sonhos, fazendo o que a gente quer. É claro que a gente tem muita dificuldade, eu tenho dificuldade principalmente nas exatas, química, física, mas eu vejo que isso foi um déficit do meu ensino fundamental, porque eu fiz supletivo, fiz exame de massa, se eu estivesse estudado quem sabe no ensino regular teria sido mais fácil na EJA, mas pra mim foi superbom, aprendi muitas coisas, coisas que eu não tive contato no ensino fundamental que só fui ter contato lá, mas a gente tem capacidade de pegar, e a maioria das pessoas que estudam na EJA tem muita dificuldade por conta do dia, porque geralmente a pessoa trabalha, e a noite a pessoa já vai cansada, então tem que haver uma força de vontade muito grande da pessoa estar ali (ANTÔNIA).

Quando tem força de vontade a gente consegue tudo. Não desista dos seus sonhos, corra atrás dos objetivos, porque não é fácil superar os obstáculos, para alcançar nossos objetivos de ter um futuro melhor, e ser um exemplo para sociedade, mesmo não tendo condições, corra atrás dos seus objetivos e consiga superar tudo (FRANCISCA). 
Se a leitora, o leitor for sujeito-educando da EJA ou dela tenha sido egressa(o) haverá grande possibilidade de realizar uma interpretação em contexto, própria de quem passou por uma experiência repleta de intempéries devido aos inúmeros condicionantes negativos, mas também conseguiu conquistar muitos inéditos viáveis.

Se a leitura for realizada por alguém engajado com a EJA, pode ser que consiga refletir sobre as diferentes dificuldades por que passam esses sujeitos-educandos, mas também poderá compreender que estas não devem proibir o sonho, muito menos determinar o seu fim. Devem mobilizar a realização de inéditos viáveis, a despeito das adversidades de ordem política, social, entre outras.

\section{CONSIDERAÇÕES FINAIS}

O presente artigo resulta de uma pesquisa que teve como objetivos: traçar um perfil de sociocultural e socioeducacional de mulheres egressas da EJA, graduandas de uma universidade pública; bem como analisar as relações entre as subjetividades dessas mulheres e os condicionantes pelos quais passaram.

A mulher da EJA configura-se como sendo a migrante, trabalhadora, mãe de família e principal responsável pela subsistência de seus dependentes. Também se percebeu a baixa escolaridade de seus pais. O perfil socioeducacional aponta para a mulher da EJA que não obteve condições materiais para cursar a educação básica durante a infância e adolescência, devido a fatores de âmbito familiar e por carência de políticas de Estado.

Aponta-se para uma realidade de baixa qualidade da educação oferecida, devido à falta de políticas e práticas pedagógicas de acesso e permanência do educando da EJA e à quantidade insuficiente de escolas públicas com infraestrutura mínima para o funcionamento de turmas, principalmente em zonas rurais.

O perfil das mulheres egressas desta modalidade de ensino aponta para a necessidade ações de políticas educacionais e de práticas pedagógicas que reconheçam a materialidade negada de que são vítimas, em vistas de uma EJA como processo de inclusão e humanização. 
Atos de Pesquisa em Educação - ISSN 1809-0354

Blumenau - vol. 11, n. 2, p.444-467 ago./nov. 2016

DOI: http://dx.doi.org/10.7867/1809-0354.2016v11n2p444-467

Essas mulheres passaram inúmeras intempéries, mas, tendo clareza concreta do sonho possível de ser realizado, trabalharam na processualidade de suas histórias visando à concretização de um inédito viável: o ingresso na educação superior, como meio de ascensão social.

Conclui-se considerando que as mulheres egressas da EJA que contribuíram com a pesquisa, atribuíram status de inédito viável à conquista de uma vaga na universidade pública, que se desdobra em um sentimento de realização pessoal, devido à superação de condicionantes sociais e econômicos que historicamente deixam as mulheres à margem da educação escolar no Brasil.

Exorta-se para a necessidade de mais pesquisas sobre o campo da EJA, muitas outras questões-problemas precisam ser sistematicamente respondidas, científica e socialmente, tais como: qual o percentual de egressos da EJA que chegam à universidade como discentes nos níveis municipal, estadual, regional e nacional? Quantos concluem os cursos de graduação? Estão matriculados em que graduações? De instituições públicas ou privadas? São homens ou mulheres? Pesquisas sobre essas e outras questões precisam ser incentivadas.

\section{ALDER DE SOUSA DIAS}

Mestre em Educação pela Universidade do Estado do Pará (UEPA), Especialista em Filosofia da Educação pela Universidade Federal do Pará (UFPA) e Licenciado em Pedagogia pela UEPA. É professor efetivo em regime de tempo integral com dedicação exclusiva junto ao Curso de Licenciatura em Educação do Campo da Universidade Federal do Amapá (UNIFAP). Integrante do Núcleo de Educação Popular Paulo Freire (NEP/UEPA), da Cátedra Paulo Freire da Amazônia e do Grupo de Pesquisa em Educação, Trabalho e Formação Humana (GEFOR/UNIFAP).

\section{JÚLIA MILENA DA PAIXÃO OLIVEIRA}

Graduada em Pedagogia pela Universidade do Estado do Pará (UEPA) e pesquisadora do GEPEA/UEAP.

\section{MANOEL RAIMUNDO DOS SANTOS}

Graduado em Pedagogia pela Universidade do Estado do Pará (UEPA) e pesquisadora do GEPEA/UEAP.

\section{ODITE DAS GRAÇAS BRILHANTE DOS SANTOS}

Graduada em Pedagogia pela Universidade do Estado do Pará (UEPA) e pesquisadora do GEPEA/UEAP.

\section{REFERÊNCIAS}


Atos de Pesquisa em Educação - ISSN 1809-0354

Blumenau - vol. 11, n. 2, p.444-467 ago./nov. 2016

DOI: http://dx.doi.org/10.7867/1809-0354.2016v11n2p444-467

ARROYO, M. G. Educação de Jovens e Adultos: um campo de direitos e de responsabilidade pública. In: SOARES, L.; GIOVANETTI, M. A.; GOMES, N. L. (Orgs.). Diálogos na Educação de Jovens e Adultos.4.ed. Coleção Estudos em EJA. Belo Horizonte, MG: Autêntica, 2011.

BERNARDIM, M. L. Educação e Trabalho na perspectiva de egressos do ensino médio e estudantes universitários. In: Nuances: estudos sobre educação, Presidente Prudente, v. 24, n. 1, p. 200-217, jan./abr. 2013. Disponível em:<http://revista.fct.unesp.br/index.php/Nuances/article/viewFile/2168/bernardim>. Acesso em: 19 mar. 2015.

BERTAUX, D. Narrativas de vida: a pesquisa e seus métodos. Natal-RN: EDUFRN; São Paulo: Paulus, 2010.

BRASIL. Constituição (1988). Constituição da República Federativa do Brasil. Disponível em:

http://www.senado.gov.br/legislacao/const/con1988/CON1988 04.02.2010/CON198 8.pdf. Acesso em: 19 mar. 2015.

. Lei de Diretrizes e Bases da Educação Nacional N. 9.394/1996.Disponível em:<http://portal.mec.gov.br/arquivos/pdf/ldb.pdfhttp://portal.mec.gov.br/arquivos/pdf/

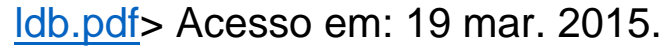

. Resolução CNE/CEB N. 3 de 15 de junho de 2010. Institui Diretrizes Operacionais para a Educação de Jovens e Adultos nos aspectos relativos à duração dos cursos e idade mínima para ingresso nos cursos de EJA; idade mínima e certificação nos exames de EJA; e Educação de Jovens e Adultos desenvolvida por meio da Educação a Distância. Diário Oficial da União, Brasília, DF, 16 de junho de 2010, Seção 1, p. 66. Disponível

em:<http://portal.mec.gov.br/index.php?option=com docman\&view=download\&alias $=5642-$ rceb003-10\&category slug=junho-2010-pdf\&ltemid=30192 >. Acesso em: 19 mar. 2015.

DIAS, A. de S.; OLIVEIRA, I. A. de; MOTA NETO, J. C. da. Pesquisas em Educação de Jovens e Adultos no Brasil: a presença de Paulo Freire. In: Anais... 35a Reunião Anual da Associação Nacional de Pós-Graduação Pesquisa em Educação. 2012. Disponível em:

<http://35reuniao.anped.org.br/images/stories/trabalhos/GT18\%20Trabalhos/GT181389 int.pdf $>$.Acesso em: 25mai. 2016.

DIAS, A. de S. Ética da Libertação e Educação: por novos horizontes à Educação de Jovens e Adultos. In: Revista Filosofia e Educação, Campinas, v. 7, n. 1, p. 159-172, fev./mai. 2015. Disponível em:

<http://ojs.fe.unicamp.br/ged/rfe/article/view/6180/5891>. Acesso em: 25 mai. 2016.

DUSSEL, E. Ética da Libertação na Idade da Globalização e da Exclusão.4.ed.

Petrópolis-RJ: Vozes, 2012. 
Atos de Pesquisa em Educação - ISSN 1809-0354

Blumenau - vol. 11, n. 2, p.444-467 ago./nov. 2016

DOI: http://dx.doi.org/10.7867/1809-0354.2016v11n2p444-467

FARIA, E. Dicionário Latino-Português. Belo Horizonte: Garnier, 2003.

FREIRE, A. M. A. Inédito viável. In: STRECK, D.; REDIN, E.; ZITKOSKI, J. Dicionário Paulo Freire. Belo Horizonte: Autêntica, 2008.

FREIRE, P. Extensão ou comunicação? 8ª ed. São Paulo: Paz e Terra, 1985.

. Pedagogia da esperança: um reencontro com a Pedagogia do Oprimido. Rio de Janeiro: Paz e Terra, 1992.

. Pedagogia da Indignação. São Paulo: UNESP, 2000.

Pedagogia dos Sonhos Possíveis. São Paulo: UNESP, 2001.

Pedagogia da Autonomia: saberes necessários à prática educativa. 23 ed.

São Paulo: Paz e Terra, 2002.

. Pedagogia da Tolerância. São Paulo: UNESP, 2004.

. A educação na cidade.6ª ed. São Paulo: Cortez, 2005.

Pedagogia do Oprimido.54를 ed. Rio de Janeiro: Paz e Terra, 2014.

HADDAD, S. (Coord.). Educação de Jovens e Adultos no Brasil (1986-1998).

Brasília-DF: MEC/INEP/COMPED, 2002.

. Prefácio. In: SOARES, L. (Org.). Educação de Jovens e Adultos: o que revelam as pesquisas. Belo Horizonte: Autêntica, 2011.

JARDILINO, J. R. L.; ARAÚJO, R. M. B. Educação de Jovens e Adultos: sujeitos, saberes e práticas. São Paulo: Cortez, 2014.

LIMA, C.; STECANELA, N.; POLETTO, L. B. As questões de gênero e a trajetória de mulheres na EJA. In: STECANELA, N.et al.(Orgs.). Ler e escrever o mundo: a EJA no contexto da educação contemporânea. Caxias do Sul-RS: EDUCS, 2014.

MARCARINI, C. T.; MÉNDEZ, N. P. Gênero, geração e patriarcado: a EJA na construção da resistência e autonomia das mulheres. In: STECANELA, N.et al.(Orgs.). Ler e escrever o mundo: a EJA no contexto da educação contemporânea. Caxias do Sul-RS: EDUCS, 2014.

MINAYO, M. C. S. (Org.). Pesquisa Social: teoria, método e criatividade. 29aㅡ ed. Petrópolis- RJ: Vozes, 2010.

OLIVEIRA, M. K. Jovens e adultos como sujeitos de conhecimento e de aprendizagem. In: Revista Brasileira de Educação, v. 1, n. 12, p. 59-73, set./out./nov./dez. 1999. Disponível em: 
Atos de Pesquisa em Educação - ISSN 1809-0354

Blumenau - vol. 11, n. 2, p.444-467 ago./nov. 2016

DOI: http://dx.doi.org/10.7867/1809-0354.2016v11n2p444-467

$<$ http://anped.org.br/rbe/rbedigital/RBDE12/RBDE12 06 MARTA KOHL DE OLIVE IRA.pdf>.Acesso em: 19 mar. 2015.

OLIVEIRA, I. A. de. Filosofia da Educação: reflexões e debates. $2^{\underline{a}}$ ed. Petrópolis-RJ: Vozes, 2011.

SAUL, A. M; SILVA, A. F. G. O legado de Paulo Freire para as políticas de currículo e para a formação de educadores no Brasil. In: R. bras. Est. pedag., Brasília, v. 90, n. 224, p. 223-244, jan./abr. 2009.

STRECK, D.; REDIN, E.; ZITKOSKI, J. (Orgs.) Dicionário Paulo Freire. Belo Horizonte: Autêntica, 2008.

Artigo recebido em abril de 2016. Aprovado em junho de 2016. 